\title{
Intravenous sedation for control of distress during lumbar punctures for pediatric cancer patients
}

\author{
Jacqueline Ellis RN PhD ${ }^{1}$, Patricia McCarthy RN MScA ${ }^{2}$, Pierre Gosselin $\mathrm{PhD}^{1}$, William Splinter MD FRCPC ${ }^{2}$
}

\author{
J Ellis, P McCarthy, P Gosselin, W Splinter. \\ Intravenous sedation for control of distress during lumbar \\ punctures for pediatric cancer patients. \\ Pain Res Manage 2000;4(2):141-147.
}

OBJECTIVE: To compare the sedative and amnestic effects, the rapidity of recovery, and the adverse effects of midazolam and propofol for intravenous sedation. The focus of this paper is the effects of intravenous sedation on distress, the acceptability to parents of this intervention for helping their children cope with painful procedures and the utility of an intravenous sedation program administered by an anesthetist.

PATIENTS AND METHODS: Twenty six children were randomly assigned to intravenous sedation with either midazolam or propofol as the first drug received. Self-report measures of anxiety and fear were assessed before and $30 \mathrm{~min}$ after the lumbar puncture (LP). Self-report of pain was also assessed 30 min postLP. The children were videotaped during the LP, and the tapes were coded for pain and negative emotion using the Emotion Facial Action Coding System. One parent completed the acceptability questionnaire while the child was in the recovery room.

RESULTS: Only three children indicated pain on the Visual Analogue Scale, and two children had facial expressions indicative of pain during the LP. Fear and anxiety differed as a function of procedure order, and children were more fearful and anxious before the first sedated LP than the second. Intravenous sedation was highly acceptable to parents, and neither drug was considered superior.

CONCLUSIONS: Intravenous sedation with either propofol or midazolam, in combination with analgesia, was effective for alleviating pain and emotional distress associated with LPs. Although children were told that the sedation would make them relaxed and sleepy, they remained somewhat fearful until they experienced a comfortable LP. The benefits of an anesthetist-administered intravenous sedation program are discussed.

Key Words: Intravenous sedation; Pediatric cancer pain; Procedural distress

\section{Sédation intraveineuse pour soulager l'angoisse durant les ponctions lombaires chez les enfants cancéreux}

OBJECTIF : Comparer les effets sédatifs et amnésiques ainsi que les effets indésirables de la sédation intraveineuse au midazolam et au propofol, de même que la rapidité de récupération des enfants. Le présent article porte sur les effets de la sédation intraveineuse sur l'angoisse, l'acceptabilité de l'intervention auprès des parents pour aider leur enfant à subir une intervention douloureuse et l'utilité de la sédation intraveineuse administrée par un anesthésiste.

PATIENTS ET MÉTHODE : Vingt-six enfants ont été soumis au hasard à la sédation intraveineuse au midazolam ou au propofol comme premier médicament. Il y a eu auto-évaluation de l'anxiété et de la crainte avant la ponction lombaire (PL) et 30 minutes après l'intervention ainsi qu'une auto-évaluation de la douleur 30 minutes après la PL. L'intervention a été enregistrée sur bande vidéo et l'expression de la douleur et d'émotions négatives sur le visage a été codée selon l'échelle Emotional Facial Action Coding System. Un parent a rempli le questionnaire sur l'acceptabilité de l'intervention pendant que son enfant était dans la salle de réveil.

RÉSULTATS : Seulement trois enfants ont indiqué de la douleur sur l'échelle analogique visuelle et deux enfants ont eu des expressions faciales révélatrices de douleur durant la PL. Le degré de crainte et d'anxiété variait selon l'expérience personnelle : les enfants étaient plus anxieux et craintifs avant la première PL sous sédation qu'avant la deuxième. La sédation intraveineuse s'est révélée une mesure tout à fait acceptable auprès des parents et aucun médicament ne s'est montré supérieur à l'autre.

CONCLUSIONS : La sédation intraveineuse au propofol ou au midazolam, ajoutée à l'analgésie, s'est avérée efficace pour diminuer la douleur et l'angoisse associées aux PL. Même si les enfants savaient que la sédation les rendrait détendus et somnolents, ils restaient quelque peu craintifs jusqu'à ce qu'ils fassent l'expérience d'une PL non douloureuse. Il sera question ici des avantages de la sédation intraveineuse administrée par un anesthésiste.

\footnotetext{
${ }^{1}$ University of Ottawa, and ${ }^{2}$ Children's Hospital of Eastern Ontario, Ottawa, Ontario

Correspondence: Jacqueline Ellis, School of Nursing, University of Ottawa, 451 Smyth Road, Ottawa, Ontario K1H 8M5.

Telephone 613-562-5800 ext 8422, fax 613-562-5443, e-mail jellis@uottawa.ca
} 
$\mathrm{T}$ reatment advances such as antitumour drugs, new combinations of chemotherapy, bone marrow transplantation and immune modulators have substantially improved long term survival rates for most pediatric cancers (1). While increasingly effective, the treatment for cancer is also complex, intrusive and burdensome. For example, children diagnosed with leukemia typically undergo four lumbar punctures (LPs) and two bone marrow aspirations (BMAs) in the first month of an active treatment regimen that can last as long as 36 months (2). These painful procedures have been identified by children and adolescents as the most difficult aspect of cancer treatment (3). The pain, anxiety and distress associated with these procedures are considerable and, for some, intolerable. A number of nonpharmacological interventions have been used with some success to help children cope with procedural pain and distress (4). However, very young children or children who are not interested in using these techniques need other options. Increasingly, oncology centres in North America are using intravenous sedation during BMAs and LPs $(5,6)$. The primary goal of intravenous sedation for procedural distress is the establishment of a state of relaxation with intact protective reflexes (7). Ideally, there is minimal alteration in blood pressure, heart rate and oxygen saturation levels, and children have limited recall and experience minimal distress during and after the procedure $(8,9)$. Children who experience comfortable procedures are less likely to be anxious and fearful during the procedure, and are less likely to develop anticipatory anxiety that manifests as nausea, vomiting, anorexia, nightmares and depression in the days preceding a scheduled procedure (10). Benefits to the staff when children are comfortable and cooperative include decreased stress and decreased time to perform procedures, which result in decreased costs to the health care system (11).

Midazolam and more recently propofol are the two most frequently used drugs for intravenous sedation $(6,8,12)$. Neither of these drugs has analgesic effects, and procedural pain must be prevented with supplemental analgesia. There is an additive effect when using sedative agents and opioid analgesia, which makes it possible to decrease the dosages of both drugs (13). A short acting narcotic such as fentanyl, a local anesthetic cream (lidocaine/prilocaine [EMLA, AstraZeneca, Canada) and local infiltration of $1 \%$ lidocaine at the puncture site are typically used in combination to prevent pain $(9,14)$.

The initial purpose of the study was to compare the sedative and amnestic effects, the rapidity of recovery, and the adverse effects of midazolam and propofol for sedation. Results of this part of the study indicated that both drugs provided excellent sedation and amnesia, and children administered propofol awakened slightly faster and experienced slightly less vomiting than children given midazolam (15). The focus of this paper is the effects of intravenous sedation on distress, the acceptability to parents of this intervention for helping their children cope with LPs and the utility of an intravenous sedation program administered by an anesthetist.
Parental acceptability of intravenous sedation was included as part of the evaluation process because parents are encouraged to remain with their child during procedures, and often at least one parent is present. The overall evaluation of a treatment is typically based on its safety and effectiveness, and whether it is an improvement over standard treatments. Criteria to evaluate treatment acceptability were proposed to broaden the focus of evaluation to include issues sensitive to the consumer's perspective. Treatment acceptability is the extent that individuals (ie, lay persons, clients, consumers) believe an intervention to be reasonable, relatively free of risk and negative side effects, and appropriate for the situation (16). Measures of treatment acceptability were initially developed to evaluate behavioural and pharmacological interventions for child behaviour problems in educational, institutional and home situations (17-20). More recently, the construct has been assessed to evaluate pain management strategies for children undergoing invasive medical procedures (21). Poor patient and parental acceptability have been suggested as an explanation for why recommended treatments or interventions are underused.

\section{Participants}

\section{PATIENTS AND METHODS}

All children three years of age and older who were required to undergo multiple LPs as part of cancer treatment were eligible to participate in the study. Children were excluded from the study if they had an allergy to one of the study drugs, an alternative sedation technique was preferred by the child and/or family, the child and/or family was unable to comprehend English or French, or the child was concurrently receiving other sedative agents. Only two children declined participation in the study because they preferred an alternative sedation technique.

\section{Measures}

Acceptability: The Acceptability Questionnaire (AQ) (21) was developed to assess the acceptability of pharmacological and cognitive-behavioural pain management strategies for children undergoing LPs and BMAs. The nine items in the AQ were patterned after existing treatment acceptability measures but are more appropriate for assessing interventions used for distress reduction during medical procedures. In a series of four studies, the AQ demonstrated convergent, discriminant and predictive validity, stable test-retest reliability $(\mathrm{r}=0.92)$ and internal consistency $(\mathrm{r}=0.90)$. Patients respond to the nine items on the AQ on a six-choice Likertlike scale ranging from 'strongly disagree' to 'strongly agree'. Scores are summed and range from nine to 54 , with higher scores indicating greater acceptability. A score in the mid-30s indicates minimal acceptability (21).

Self-report of anxiety, fear and pain: Children aged six years and older responded to two questions about their experience of anxiety and fear before and during the procedure. The following questions were asked 1 min before sedation and $30 \mathrm{~min}$ after sedation, respectively: "how anxious are you right now?" and "how anxious were you during your pro- 
cedure?", and "how afraid are you right now?" and "how afraid were you during your procedure?" Responses were recorded on a $100 \mathrm{~mm}$ Visual Analogue Scale (VAS) with the anchors 'no fear' or 'no anxiety', and 'fear as great as possible' or 'anxiety as great as possible'. Similarly, $30 \mathrm{~min}$ after sedation, children were asked, "How much did it hurt during the procedure?" They responded by marking a VAS with the anchors 'not at all' and 'very much'.

Behavioural indicators of pain and emotion: Behavioural indicators of pain and emotion were assessed with the Emotion Facial Action Coding System (EMFACS), developed by Ekman et al (22). This system is an abbreviated version of Ekman and Friesen's (23) more extensive Facial Action Coding System (FACS). Whereas FACS requires the coder to score any one of the possible 44 action units, EMFACS focuses only on the action unit combinations that are theoretically and experimentally related to emotion expression. For the purpose of the present study, all facial expressions of fear, anger, sadness and disgust were scored.

EMFACS-coded action unit combinations were classified into emotion categories by using the repertoire proposed by Ekman and Friesen (23). This repertoire includes the most common action unit combinations that have been found to be associated with basic emotions. The validity of this repertoire has been supported by several studies in adults (24-26) and in children (27-29). Previous studies consistently reported good intercoder reliability $(80 \%$ or higher) with FACS and EMFACS in adults, and with FACS in children. The authors are not aware of any intercoder reliability data with EMFACS in children. However, intercoder reliability has generally been found to be higher with EMFACS than with FACS in adults $(30,31)$.

Because EMFACS does not provide descriptions of pain expressions, the authors adapted it by using the descriptions provided by Prkachin (32) in a study examining the consistency of facial expressions for different types of pain. Prkachin (32) found that combinations of four action units (AU) were consistently related to pain: brow lowering (AU 4), orbit tightening (AU 6 or AU 7), levator contraction (AU 9 or AU 10) and eye closure (AU 43). Within this subset, the greatest amount of variance was accounted for by orbital and levator action. When coding the material for the present study, children were considered to be in pain when at least two of these four actions, the orbit tightening (AU 6 or AU 7) and the levator contraction (AU 9 or AU 10), occurred simultaneously.

Sedation scale: The level of sedation was judged on a numerical scale that ranged from 1 to 6 . The numerical descriptors included 'no effect', 'mild', 'moderate', 'marked', 'unconscious' and 'anesthetized'. The target level for sedation during the lumbar puncture was 3 (moderate), which was indicated by slurred speech, rousing to nonpainful stimuli and obeying repeated commands. This sedation scale is an adaptation of published scales and is used by the anesthesia department in the study hospital. Sedation scores were recorded at 5,10 and 15 min after the sedative drug was administered.
Procedure time: The timing of the procedure started when the cleansing solution was applied to the lumbar puncture site and ended when the needle was withdrawn from the site.

Recovery patterns: Recovery from anesthesia was assessed with the Aldrete Recovery Scale (33). Scores range from 0 (unconscious) to 10 (awake). The children were scored 0, 5, 10 and $15 \mathrm{~min}$ after the procedure. Time 0 was considered to be when they entered the recovery room.

\section{Procedures}

The study received ethical approval from the Ethical Review Committee at the study hospital. Children (and their parents) between the ages of three and 16 years undergoing cancer treatment who required LPs were invited to participate in the study. Parents and children were told that two sedatives used to control distress during LPs were being compared. Verbal assent was obtained from children seven years and older, and one parent signed a consent form. Children were then randomly assigned to one of two study groups based on the sequence of drug administration. Group 1 received propofol for the first LP and then midazolam for the second LP. Group 2 received the drugs in reverse order - midazolam first, then propofol.

One or both parents remained with their child during the procedure. Before being given any medications, children were shown how to use the VAS and then asked to rate their anxiety and fear. The LP was videotaped by a research assistant, and the videotape recorder was activated when the children were assisted to the examining table and stopped after the LP was completed.

Intravenous sedation medications were administered by the same anesthetist throughout the study. The anesthetist was in attendance until the patient was discharged from the procedure room to the observation unit for recovery. The sequence of events related to sedation were as follows.

1. EMLA cream was placed on the portacath and LP site.

2. Approximately $1 \mathrm{~h}$ later, an intravenous line was established, and pulse oximetry and blood pressure monitoring were implemented in accordance with the hospital's intravenous sedation protocol.

3. Fentanyl $1 \mu \mathrm{g} / \mathrm{kg}$ was administered intravenously followed by the study drug approximately 2 min later.

4. Propofol was administered in an initial dose of $1 \mathrm{mg} / \mathrm{kg}$ followed by $0.5 \mathrm{mg} / \mathrm{kg}$ every $2 \mathrm{~min}$ until a sedation level of 3 was achieved.

5. Midazolam was administered in an initial dose of $100 \mu \mathrm{g} / \mathrm{kg}$ followed by $50 \mu \mathrm{g} / \mathrm{kg}$ every 3 min until a sedation level of 3 was achieved.

Upon completion of the LP, children were transferred from the procedure room to an observation unit where Aldrete recovery scores, vital signs and oxygen saturation were monitored. Thirty minutes after awakening, children were asked to rate the pain, anxiety and fear that they experienced during the procedure. At this time, the parent who accompanied the child during the LP was asked to complete the AQ. 
TABLE 1

Means and standard deviations for anxiety and fear as a function of procedure order

\begin{tabular}{llccc}
\hline Variable & & Procedure 1 & Procedure 2 & P \\
\hline Fear & Before & $23.7 \pm 29.3$ & $11.2 \pm 15.6$ & 0.05 \\
& After & $2.9 \pm 7.0$ & $0 \pm 0$ & 0.002 \\
Anxiety & Before & $32.3 \pm 28.8$ & $7.2 \pm 13.0$ & 0.01 \\
& After & $10.8 \pm 22.2$ & $2.0 \pm 6.6$ & 0.01 \\
\hline
\end{tabular}

Fear and anxiety are measured on a $100 \mathrm{~mm}$ visual analogue scale

TABLE 2

Number of children who expressed pain and negative emotions per procedure and time

Procedure $1(n=23) \quad$ Procedure $2(n=15)$

Time 1 Time 2 Time 3 Time 1 Time 2 Time 3

\begin{tabular}{lllllll} 
Pain & 2 & 2 & 1 & 2 & 0 & 0 \\
Sadness & 1 & 0 & 0 & 1 & 0 & 1 \\
Fear & 1 & 0 & 0 & 0 & 0 & 0 \\
Disgust & 0 & 0 & 0 & 0 & 0 & 0 \\
\hline
\end{tabular}

Time 1 Before lumbar puncture (LP); Time 2 During LP; Time 3 After $L P$

\section{RESULTS}

\section{Participants}

Twenty-six children were initially enrolled in the study, and a complete data set was available for 21 children. Reasons for dropping out of the study included completion of treatment and death. The children ranged in age from three to 14 years, and the average age was 7.5 years. Thirteen males and eight females underwent LPs for diagnostic or treatment purposes. All of the children in the study had a diagnosis of either leukemia or lymphoma. The time between LPs was associated with the phase of treatment the children were in at the time of the study. Five children were in the early phases of treatment, and the time between LPs varied from two to 14 days. The rest of the children were in the maintenance phase of treatment, and the time between LPs varied from eight to 12 weeks.

\section{Sedation scores, procedure and recovery time}

The average sedation score at $5 \mathrm{~min}$ was similar for midazolam (mean 3.2, SD 0.70) and propofol (mean 3.7, SD 0.84) $(\mathrm{P}>0.05)$, as was the amount of time to perform the lumbar punctures (midazolam - mean 8.7 min, SD 3.8; propofol mean $8.3 \mathrm{~min}$, SD 3.3, $\mathrm{P}>0.05$ ). Children administered propofol awakened significantly faster than children administered midazolam. The mean Aldrete recovery scores at time $0,5,10,15$ and 20 min ranged from 0.7 to 1.0 greater in the propofol group (all $\mathrm{P}>0.05$ ) compared with the midazolam group.

\section{Pain, anxiety and fear}

Very little pain was reported with either midazolam or propofol. One child reported pain of 2.8 on the $100 \mathrm{~mm}$ VAS in the midazolam group and two children reported pain of 7.5 and
TABLE 3

Number of children who expressed pain and negative emotions per drug and time

\begin{tabular}{lcccccc}
\hline & \multicolumn{2}{c}{ Midazolam $(\mathbf{n}=\mathbf{1 9})$} & \multicolumn{3}{c}{ Propofol $(\mathbf{n = 1 9 )}$} \\
& Time 1 & Time 2 & Time 3 & Time 1 & Time 2 & Time 3 \\
\hline Pain & 2 & 1 & 0 & 2 & 1 & 1 \\
Sadness & 1 & 0 & 1 & 1 & 0 & 0 \\
Fear & 1 & 0 & 0 & 0 & 0 & 0 \\
Disgust & 0 & 0 & 0 & 0 & 0 & 0 \\
\hline
\end{tabular}

Time 1 Before lumbar puncture (LP); Time 2 During LP; Time 3 After LP

10.3 , respectively, in the propofol group. Similarly, the mean scores for fear and anxiety did not differ according to which drug was administered.

Fear and anxiety were examined as a function of procedure order to determine whether emotional state differed according to whether it was the child's first or second lumbar puncture performed with intravenous sedation. The scores for fear and anxiety were transformed using a square root transformation to account for heterogeneity of variance in the distributions for these variables. The transformed scores were used in a $2 \times 2([$ procedure 1 , procedure 2$] \times$ [baseline, postprocedure]) within-subjects ANOVA. Children's anxiety decreased significantly before the second procedure, and fear approached significance. Both fear and anxiety decreased from baseline to postprocedure. See Table 1 for means and standard deviations.

Facial expression: A total of 46 procedures were recorded, and of these, eight were discarded due to technical problems; therefore, the coding was performed with the remaining 38 complete procedures. Two coders, who were blind to the episodes (before, during and after LP), procedure order and drugs, scored the facial videotaped material. These individuals had previously passed the efficiency test designed by Ekman and Friesen (23). Each coder scored all of the material. The interrater reliability was $97 \%$, and disagreement was resolved by discussion.

Pain and negative emotions were infrequent immediately before, during or after the LPs (Table 2). Pain was observed in two children during the first LP and not at all during the second procedure. Similarly, sadness, fear and disgust were infrequent and were never observed during the LPs.

Table 3 shows the number of children who expressed pain, sadness, fear and disgust as a function of which drug was administered. The occurrences of pain and negative emotions were comparable for midazolam and propofol (Table 3).

Acceptability: Parents found both drugs equally acceptable, and there was no significant difference between the two drugs. The mean acceptability score for midazolam was 46.4 , (SD 6.2) and for propofol 48.4 (SD 1.4) $(\mathrm{t}=1.31, \mathrm{P}>0.05)$.

\section{DISCUSSION}

Intravenous sedation with either midazolam or propofol, in combination with analgesia, was effective for alleviating the pain and emotional distress associated with LPs. The results 
obtained from the facial behaviour were congruent with the subjective ratings provided by the children. Three children indicated that they had pain during the LP using the VAS, and two children displayed facial expressions indicative of pain during the LP. The pain self-reports and the facial expressions of pain were not from the same children. This lack of agreement between the verbal and behavioural pain expression may be related to the amnesia that is a side effect of both midazolam and propofol. The VAS pain ratings may have more accurately reflected what the children were feeling when they were asked to give a rating rather than the remembered pain during the LP. The two children who had facial expressions indicative of pain during the procedure had no recall of the pain when they were asked to rate the pain they experienced during the LP.

The videotapes indicated that the children were cooperative and did not need to be restrained during the LPs. This made the procedures easier to perform and probably less stressful for the parents to observe. It has been reported that both parents and staff are stressed by the verbal and physical protestations of children undergoing painful procedures $(6,34)$. The improved cooperation of the children contributed to a relatively short procedure time, with an average of $8 \mathrm{~min}$. Anecdotal evidence from this oncology centre suggests that this is an improvement over previous practice. Before implementing an intravenous sedation program, many children had to be verbally cajoled to cooperate and others had to be physically restrained. Depending on the age and strength of the child, it may be almost impossible to hold the child immobile and in the correct position to perform the LP efficiently. Katz and colleagues (10) describe stalling behaviours in children that are likely familiar to nurses and physicians who perform painful procedures. The child pleads, "I'll be fine if I can just use the bathroom first", "please can you let me move my legs back a bit", "let my mom sit over here," etc. In an effort to give the child some control, these requests may be accommodated. However, this may actually serve to increase the distress as the anticipatory phase of the procedure drags on, and the child and professionals are caught in a maze of stalling behaviours. It only requires a few children to exhibit these behaviours to increase the overall clinic time and number of visits devoted to intrusive procedures.

Before their first LP, children were told that intravenous sedation would make them sleepy and relaxed. The relatively high scores on the VAS for anxiety and fear before procedure 1 suggested that the children were somewhat skeptical and needed to experience a comfortable LP for themselves. The fear and anxiety decreased by at least half before procedure 2. Presumably, based on the positive experience of a low stress LP, the children approached the second procedure with greater ease and confidence. Similarly, when children experience a number of painful procedures, their distress tends to increase over time (10). They learn that it hurts the first time and that the pain does not decrease just because they are familiar with the details of the procedure. In fact, many children will have the experience of a procedure that was unusually painful and emotionally traumatic. This may be related to known and unknown factors such as the skill of the person performing the procedure, the skill of the person holding the child, the inability of the child to cooperate or an unexplained difficulty in placing the needle, which requires the child to endure many needle sticks. Traumatized children remain skeptical when told that they will experience a comfortable LP.

Intravenous sedation was highly acceptable to parents and, as expected, there was no difference between the two drugs. Midazolam and propofol had the same effect from the parents' perspective in that the child was relaxed and comfortable. In an earlier study using the AQ, Cross (21) asked mothers, based on a series of vignettes, to rate the acceptability of imagery, attention distraction and oral valium for reducing distress in children undergoing a BMA or LP. The AQ scores for imagery (41.0), oral valium (41.8) and attention distraction (42.6) were substantially lower than the acceptability for midazolam (46.4) and propofol (48.4).

A number of intravenous sedation programs that do not require an anesthetist to be present during the procedure are described in the literature. Some centres use trained nurses $(6,13)$, nurse anesthetists $(35)$ or the oncologist performing the procedure (5) to administer the drugs and monitor the children. Intravenous sedation, in this pediatric oncology centre, is always administered by an anesthetist, and the drug of choice is propofol. To accommodate families and the busy schedules of both oncology and anesthesia, BMAs and LPs are performed on Tuesdays and Thursdays between 13:00 and 15:00. An anesthetist is assigned to the clinic during these times. The oncology nurse practitioner, or a pediatric clinical assistant who is a physician, performs the procedures.

There are a number of benefits to having an anesthetist responsible for administering intravenous sedation. Most importantly, anesthetists are comfortable administering sedation and analgesia in the dosages necessary to achieve the desired effect, which is a sedated child who is immobile and comfortable. Sievers and colleagues (5) reported that, with intravenous sedation administered by the oncologist, $55 \%$ of children required 'some' or 'much' restraint during BMAs and LPs. Similarly, Macpherson and Lundblad (6) reported less intense distress, less need for restraint, and fewer and less intense verbal and behavioural manifestations of pain in a nurse-administered intravenous sedation program for procedural pain. The primary objectives for a sedation program are safety and efficacy. The fact that children still require restraint, and that pain and distress are reduced but not eliminated, suggest that the program may not be meeting the comfort needs of the children. Two children had facial expressions indicative of pain during the LP. Both of these children were given additional analgesia and sedation, and quickly achieved a state of relaxed comfort. This was possible because the anesthetist was confident in administering sufficient sedation and analgesia, and was prepared to cope with airway management if the patient moved from conscious to deep or unconscious sedation. 
Although it is no longer ethically acceptable or necessary to compare intravenous sedation with a no treatment control group, long term survivors who have relapsed provided us with interesting comparative information. These patients, now adolescents, shared their memories of feeling extreme dread and fear as they anticipated a clinic appointment where a painful procedure was scheduled. This is in contrast to the current practice of intravenous sedation, which they find to be easy and quick, with typically no unpleasant side effects.

Intravenous sedation for children undergoing painful procedures in oncology has become the gold standard of care; however, a small number of children remain distressed before the procedure and immediately after. Clinical observation indicates that these children tend to be younger, and as the initial period of novelty and relief at being sedated has subsided, more children express distress. For some children, propofol leaves a bitter taste in their mouths and, coupled with chemotherapy-induced nausea, is unpleasant. Because these are clinical observations, at this point we plan to examine the experience of intravenous sedation from the parent and child's perspective and hope to describe the predictors of distress. Other factors that may contribute to children's distress is that efforts to use cognitive behavioural strategies on

\section{REFERENCES}

1. Schwartz C, Hobbie W, Constine L, Ruccione K. Survivors of Childhood Cancer Assessment and Management. St Louis: Mosby, 1994.

2. Tubergen D, Gilchrist G, O'Brian R, et al. Prevention of CNS disease in intermediate risk acute lymphoblastic leukemia: comparison of cranial radiation and intrathecal methotrexate and the importance of systemic therapy: a Children's Cancer Group report. J Clin Oncol 1993;11:520-6.

3. McGrath PJ, Hsu E, Cappelli M, Luke B, Goodman J, Dunn-Geier J. Pain from pediatric cancer: A survey of an outpatient oncology clinic. J Psychosoc Oncol 1990;8:109-24

4. Ellis J, Spanos N. Cognitive-behavioral interventions for children's distress during bone marrow aspirations and lumbar punctures: A critical review. J Pain Symptom Manage 1994;9:96-108.

5. Sievers T, Yee J, Foley M, Blanding P, Berde C. Midazolam for conscious sedation during pediatric oncology procedures: Safety and recovery parameters. Pediatrics 1991;88:1172-9.

6. Macpherson C, Lundblad L. Conscious sedation of pediatric oncology patients for painful procedures: Development and implementation of a clinical practice protocol. J Pediatr Oncol Nurs 1997;14:33-42.

7. American Academy of Pediatrics Committee on Drugs: Guidelines for monitoring and management of pediatric patients during and after sedation for diagnostic and therapeutic procedures. Pediatrics 1992;89:1110-6.

8. Boyd O, Mackay J, Rushmer F, Benett E, Grounds R. Propofol or midazolam for short-term alterations in sedation. Can J Anaesth 1993;40:1142-7.

9. Zeigler V, Brown L. Conscious sedation in the pediatric population. Crit Care Nurs Clin North Am 1997;9:381-94.

10. Katz E, Kellerman J, Siegel S. Behavioral distress in children with cancer undergoing medical procedures: Developmental considerations. J Consult Clin Psychol 1980;48:356-65.

11. Perin G, Frase D. Development of a program using general anesthesia for invasive procedures in a pediatric outpatient setting. J Assoc Pediatr Oncol Nurs 1985;2:8-10.

12. Snellen F, Lauwers P, Demeyere R, Byttebeir G, Van Aken H. The use the part of parents and staff may not be as evident as when children were unmedicated.

LaMontagne and colleagues (34) reported that parents' uncertainty about preparing their child for procedures correlated with children's distress and coping behaviours during procedures. They noted that situations involving high levels of responsibility and low control are likely to generate feelings of stress in the parents. Even though the child is sedated during the procedure, it may be helpful to offer parents information about cognitive behavioural strategies that may alleviate pre- and postprocedural distress.

\section{CONCLUSIONS}

Intravenous sedation with either propofol or midazolam in combination with analgesia is an effective means to alleviate pain and emotional distress associated with LPs. Once children experience comfortable LPs, they tend to be less fearful and anxious with subsequent procedures. An intravenous sedation program administered by anesthesia has benefits for patients, family and staff. The organizational and scheduling efforts, and the commitment to relieving procedural pain and distress, are essential for best-practice pediatric cancer care. of midazolam versus propofol for short-term sedation following coronary artery bypass grafting. Intensive Care Med 1990;16:312-6.

13. Watson D, James D. Intravenous conscious sedation: Implications of monitoring patients receiving local anesthesia. AORN J 1990;51:1512-25.

14. Halperin D, Koren G, Attias D, Pellegrini E, Greenberg M, Wysss M. Topical skin anaesthesia for venous, subcutaneous drug reservoir, and lumbar punctures in children. Pediatrics 1989;84:281-2.

15. Splinter W, Hsu E, McCarthy P. Sedation in paediatric oncology procedures: propofol vs midazolam. Can J Anesth 1996;43:82 (Abst 44A)

16. Wolf M. Social validity: The case for subjective measurement or how applied behavior analysis is finding its heart. J Appl Behav Anal 1978;11:203-14.

17. Kazdin A. Acceptability of alternative treatments for deviant child behavior. J Appl Behav Anal 1980;13:259-73.

18. Kazdin A, French N, Sherick B. Acceptability of alternative treatments for children: Evaluations by inpatient children, parents, and staff. J Consult Clin Psychol 1981;49:900-7.

19. Cross CS, McMahon R. The treatment acceptability of a behavioral parent training program and its components. Behav Ther 1987;2:165-79.

20. Cross CS, Johnston C. Acceptability for child behavior problems: Issues and implications for future research. J Clin Child Psychol 1990;19:61-74.

21. Cross CS. Acceptability of psychological interventions for pediatric pain associated with invasive medical procedures. Dissertation Abstr Int 1992;54-06B:3335.

22. Ekman P, Irwin W, Rosenberg ER, Hager, JC. FACS Affect Interpretation Data Base. [Computer Data Base]. San Francisco: University of California, 1995.

23. Ekman P, Friesan WV. The Facial Action Coding System (FACS): A Technique for the Measurement of Facial Action. Palo Alto: Consulting Psychologists Press, 1978.

24. Ekman P, Friesen WV, Ancoli S. Facial signs of emotional experience. J Personality Social Psychol 1980;39:1125-34.

25. Gosselin P, Kirouac G, Doré F. Components and recognition of facial 
expression in the communication of emotion by actors.

J Pers Soc Psychol 1995;68:83-96.

26. Rosenberg E, Ekman P. Coherence between expressive and experiential systems in emotion. Cognit Emotion 1994;8:201-29.

27. Ekman P, Hager JC, Friesen WV. The symmetry of emotional and deliberate facial actions. Psychophysiology 1981;18:101-6.

28. Josephs I. Display rule behavior and understanding in preschool children. J Nonverbal Behav 1994;18:301-26.

29. Soussignan R, Schaal B. Children's facial responsiveness to odors: influences of hedonic valence of odor, gender, age, and social presence. Dev Psychol 1996;32:367-79.

30. Ekman P, Matsumoto D, Friesen WV. Facial expression in affective disorders. In: Ekman P, Rosenberg E, eds. What the Face Reveals: Basic and Applied Studies of Spontaneous Expression Using the
Facial Action Coding System (FACS). New York: Oxford University Press, 1997:331-41.

31. Steimer-Krause E, Krause R, Wagner G. Interaction regulations used by schizophrenic and psychosomatic patients: Studies on facial behavior in dyadic interactions. Psychiatry 1990;53:209-28.

32. Prkachin K. The consistency of facial expressions of pain: A comparison across modalities. Pain 1992;51:297-306.

33. Aldrete JA. Recovery room score card. AORN J 1973;17:79-83.

34. LaMontagne L, Wells N, Hepworth J, Johnson B, Manes R. Parent coping and child distress behaviors during invasive procedures for childhood cancer. J Pediatr Oncol Nurs 1999;16:3-12.

35. Warner T. Clinical applications for pediatric sedation. Clin Forum Nurs Anesthet 1997;8:144-51. 


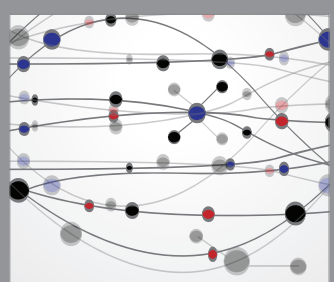

The Scientific World Journal
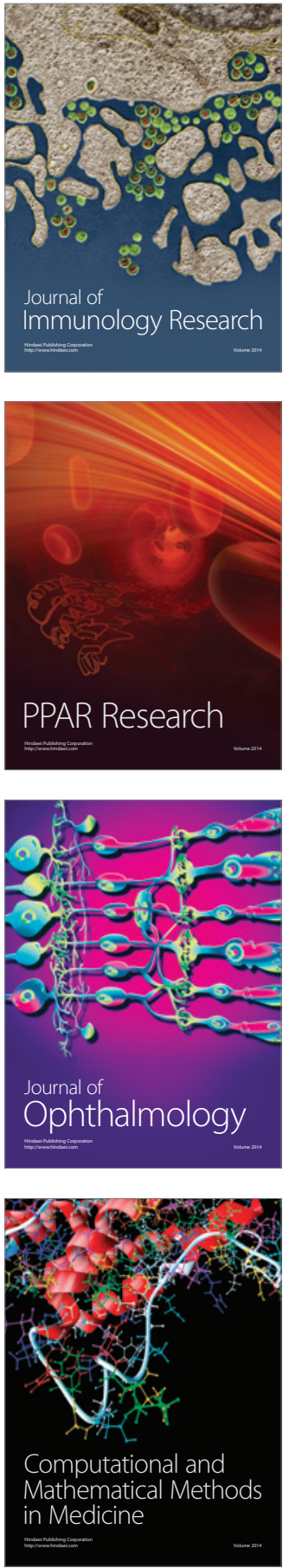

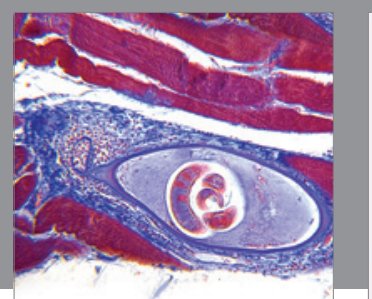

Gastroenterology Research and Practice

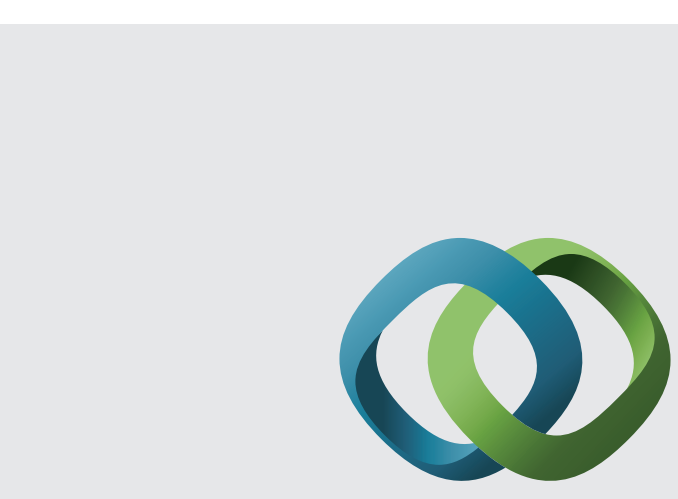

\section{Hindawi}

Submit your manuscripts at

http://www.hindawi.com
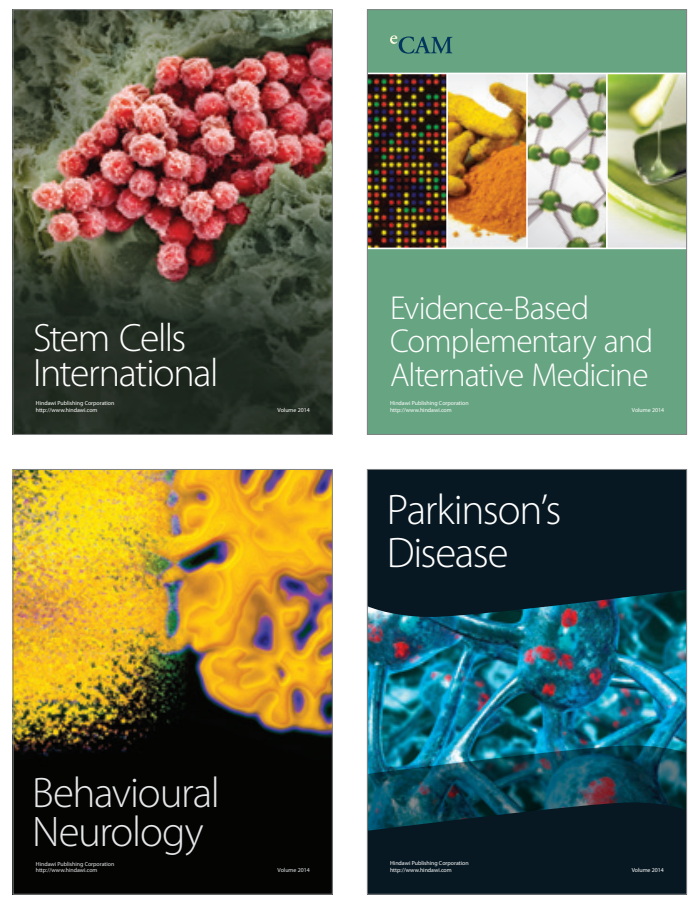
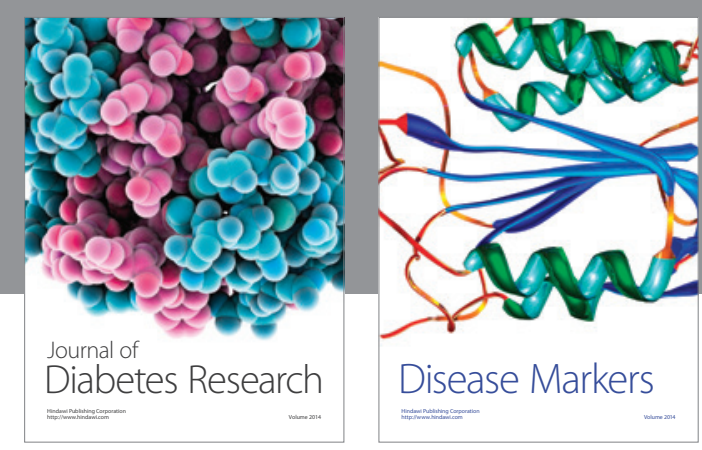

Disease Markers
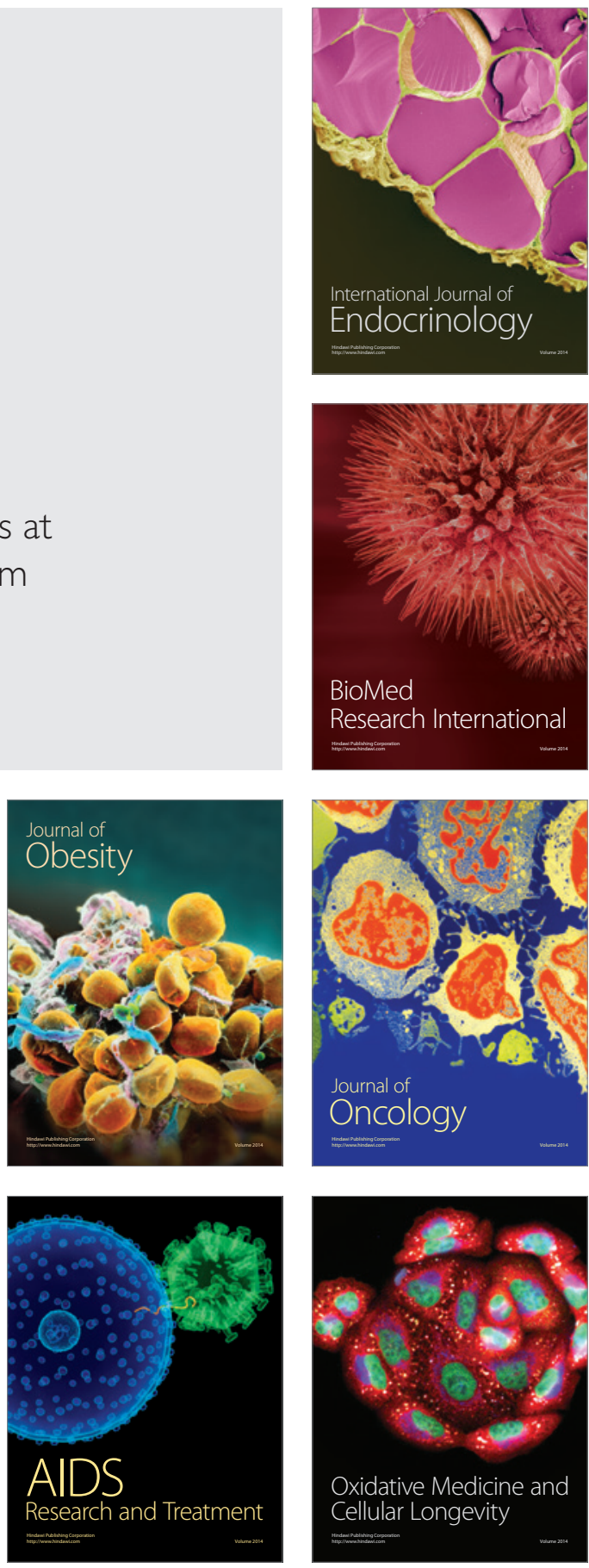